\section{Comparative Insights The Dutch Study American Higher Education}

\section{Gerhard Smid}

Gerhard Smid was a facilitator of the Boston Program for Professional Development, and is management consultant and faculty member of SIOO, a professional graduate school for organizational sciences and change management linked to the University of Amsterdam. Address: SIOO, Radboudkwartier 315, 3511 CL Utrecht, Netherlands. FAX 31 30-233-1 148.

$\mathrm{I}^{\mathrm{n}}$ n October 1996 a group of 14 people-including deans, managers, vice presidents, and the rector of the University of Amsterdam, made a working visit to the Boston area. The two-week meeting, the Boston Program for Professional Development, was organized by Hans de Wit, vice president for international affairs of the University of Amsterdam, and Philip Altbach of Boston College, with the help of Sandra Elman and Patricia Murphy. The program was designed to enable these experienced Dutch university managers to learn from exposure to a different educational context. The purpose was, as Bertolt Brecht said, "to make the usual unusual."

Boston College served as a base, where the group was first introduced to the administrative structure and culture of American higher education, as well as the financing of an American university.

Boston College served as a base, where the group was first introduced to the administrative structure and culture of American higher education, as well as the financing of an American university. The group then dispersed, with participants going in pairs for internships to Boston College, Northeastern University, Tufts University, and the University of Massachusetts. At each school the Dutch participants were linked to key administrators-such as deans, deans for academic affairs, professors, vice presidents, enrollment managers, and fund-raisers. It was exciting to get an inside look at university administration.

The participants were also taken on group visits to the above-mentioned schools, as well as to Harvard University and the Massachusetts Board of Higher Education, which exposed each member of the delegation to at least four universities and a closer view of one. Some group members arranged additional activities-a tour of a science park (on Route 128) and visits having to do with architectural issues of facility management. We also partook of cultural aspects of university life-such as the installation of the new president of Boston College, a college football game, and some good informal discussions with students.

The tour was quite an investment in time and money. Though the group has not yet evaluated the results of the trip, we can give an impression of the added value of such a learning tour. To do this properly, I first have to give some background on the Dutch situation. In the Netherlands nearly all universities (14) and professional schools (56) are governed and fully financed by the state. Since 1980, however, slow but steady changes have been taking place. As of 1995, most universities were drawing 35 percent of their income from state resources. This constituted a shift away from state-supported toward state-assisted universities. A number of demographic factors led to a process of competition among universities for students, beginning in the mid1980s. These developments have not only created pressures on the management and administration of these organizations, but also introduced diversity into the Dutch university system. A law offering universities greater freedom to choose their own structures and strategies will soon go into effect. To meet these new developments, university administrators have become interested in learning from others. The Boston area, with its great density of universities and colleges, offers an excellent place to study developments that may be relevant in the Netherlands.

\section{In the Netherlands, the research culture predominates. Undergraduate educa- tion is not the main issue. In truth, some faculty are not really interested in stu- dents. In Boston, we saw a massive in- vestment in databases on students and alumni.}

The participants came away with many impressions and observations:

- The high profile of universities outside and inside the institutions is really striking. Bostonians seem to be quite proud of their institutions, and that is quite a contrast to the Netherlands.

In most universities we visited, fundraising activity is one of the most important means of generating resources. It was very interesting to see how this fundraising is organized, and we learned a lot in this area. 
- In the Netherlands, the research culture predominates. Undergraduate education is not the main issue. In truth, some faculty are not really interested in students. In Boston, we saw a massive investment in databases on students and alumni. Why do people choose this university? What image does the school have? Here the student is considered as a client far more than in the Netherlands. We were struck by the tense relations between faculty and students.

- In the Netherlands, students have some formal power in university governance, but as one of the delegation members expressed it: "here they have hardly any formal power, but more influence."

- Of course, the selectivity of American universities is quite a contrast to the Netherlands, where schools are forbidden by law to select students. Quite a few members of the delegation were in favor of a nonselective system, but after their Boston experiences, they are no longer so sure about that.

- We were able to see good examples of support systems and facilities, with high morale and good customer orientation. These were good examples to learn from.

- Of course, the Dutch group was very interested in the management of change within the universities. In the Netherlands, people have spent quite a bit of time thinking about reforms and defining policy changes. To our surprise, change management seems to be no issue at all here. And still institutions change. We think that these managers are equivalent to change managers.

We saw some notable examples of transformational leadership that were in contrast to transactional leadership as it commonly exists in the Netherlands. The transformation of Boston College from a working-class college to a top-ranked institution, the challenge that Northeastern University successfully faced in responding to a 25 percent fall in student enrollment, and the handling of the exploding first-generation student population at the University of Massachusetts are impressive achievements.

Of course, we did not embark on this trip to imitate the American solutions to problems. But we all found inspiration in the great diversity of institutions, and had a great time in the various faculty clubs. In our personal contacts with American colleagues, many strategies, tactics, and behavioral models were raised and discussed. In general, such a visit broadens the horizon of our managers and deans.

\section{News of the Center for International Higher Education and the Program in Higher Education at Boston College}

ssociate Professor Karen Arnold, coordinator of the - Lprogram in Higher Education, was selected as the best teacher in the School of Education by the Graduate Students Association. The citation mentioned Dr. Arnold's high standards and her concern for students. Damtew Teferra, graduate assistant in the Center for International Higher Education, was awarded a grant for research in Ethiopia during summer 1997. The award is from the Fondation Charles Leopold Mayer, a French foundation, and is for a study of the regionalization of publishing and higher education in Ethiopia. James JF Forest, a doctoral candidate in the higher education program, has completed work on an edited volume on teaching in higher education worldwide. The book will be published by Garland Publishing. Associate Professors Karen Arnold and Ted I. K. Youn have begun work on a study of Rhodes scholars as part of an ongoing concern with gifted youth. Liz A. Reisberg, graduate assistant in the Center for International Higher Education and managing editor of the Review of Higher Education, will lead a group of management educators on a tour of Latin American countries in the fall.

Fr. Rudi Heredia, S.J. has joined the Center as a visiting scholar for the summer of 1997. Fr. Heredia is director of the Social Science Center at St. Xavier's College, Bombay, India. In the fall, Prof. Y. T. Kim of Sogang University in Seoul, Korea, will join the Center as a visiting scholar. Sogang University is the Jesuit university in Korea. Monan Professor Philip G. Altbach recently returned from a conference on academic publishing in Central and Eastern Europe, held under the auspices of the Soros Foundation in Budapest, Hungary. In June, he will participate in a meeting on "higher education in the 21st century" in London, as a representative of the Carnegie Foundation for the Advancement of Teaching. At present, the doctoral program in higher education has students from four continents.

\section{Internet Resource}

For more information on international issues in higher education, visit the Center's web site, located at:

\section{http://www.bc.edu/bc_org/avp/soe/cihe/}

